\title{
ENTRE MADRID Y BARCELONA A MEDIADOS SIGLO XIX. A PROPÓSITO DE LOS ÚLTIMOS TRABAJOS DE JAVIER GARCÍA-BELLIDO
}

\author{
Mercedes Tatjer Mir \\ Catedrática de Didáctica de las Ciencias Sociales \\ Universidad de Barcelona \\ Barcelona, España
}

Remisión Artículo: 29-2-2007

Palabras Claves: Pascual Madoz, Industrialización Barcelona siglo XIX, Cerdà, Can Ricart, Josep Oriol Bernadet.

Con sus estudios sobre Ildefonso Cerdà y Pascual Madoz, a los que tanto esfuerzo e ilusión dedicó en los últimos años Javier García-Bellido no solo hizo una contribución muy destacada a las biografías de unos personajes de amplia dimensión política y científica, sino que planteó el interés de conocer con profundidad el significativo periodo de las décadas centrales del siglo XIX español. Dicho periodo, en el que se sientan las bases del estado liberal y del que arrancan y desarrollan muchas de los grandes proyectos de modernización del país, está configurado por una generación nacida en los albores del ochocientos y que llevará a cabo su actividad durante más de tres décadas, entre 1835 y 1870 aproximadamente.

Las aportaciones de Javier García-Bellido nos han permitido a algunos investigadores catalanes ver con nueva luz este periodo que, por razones particulares, quedaba ensombrecido, a pesar de ser crucial para entender la propia realidad del hecho industrial y del desarrollo económico de la Cataluña contemporánea, al configurar el inicio de la gran etapa industrial que tantas repercusiones urbanísticas tuvo.

Como muestran claramente los textos de Javier García-Bellido incluidos en el libro sobre Pascual Madoz, este político desempeñó un papel clave en un acontecimiento urbanístico de gran trascendencia para la modernización de la ciudad de Barcelona como fue el derribo de las murallas. Precisamente, ese tema era uno de los que poco antes de su fallecimiento preocupaba a Javier y sobre el que estaba llevando a cabo con gran entusiasmo y dedicación un amplio proyecto de investigación, en colaboración con el Centro de Política del Suelo y Valoraciones que dirige el arquitecto Josep Roca Cladera en la Universidad Politécnica de Cataluña.

En relación con dicho proyecto realizaba periódicamente visitas a Barcelona, en las que tuvimos varias reuniones con él y sus colaboradores (en especial con la arquitecta italiana Sara Anna Mangiagalli) para debatir cuestiones relacionadas con la metodología y los fondos documentales a utilizar para conocer el proceso de gestión del derribo de las murallas y la venta de sus terrenos. Algunas de estas fuentes documentales habían sido tratadas en mi Tesis Doctoral y fueron objeto de varias de mis publicaciones; además de ello, coincidimos en esta temática porque precisamente entonces estaba yo ultimando un trabajo acerca del proceso de instalación y los factores de localización industrial sobre terrenos de las antiguas murallas en la zona del llamado Ensanche de Sant Antonio durante el periodo 1868 y 1874, en

ACEO Vol.1, núm. 3, febrero 2007 | ENTRE MADRID Y BARCELONA A MEDIADOS SIGLO XIX. A PROPÓSITO DE LOS 
el que se puso de relieve el interés de algunos propietarios en la compra de dichos terrenos para usos fabriles.

Una de estas visitas, concretamente en junio del 2005, fue ocasión de un nuevo encuentro. Después de recorrer la exposición "Abajo las murallas", que entonces se realizaba en el Museo d'Història de la Ciutat, y antes de tomar el puente aéreo hacia Madrid, tuvo tiempo para trasladarse al Poblenou, acompañado también de la arquitecta Susana Ruiz, para conocer con detalle el conjunto fabril de Can Ricart, del cual ya le habíamos estado hablado meses atrás en Semana Santa durante su estancia en Lorca.

La sorpresa y el interés mostrado por Javier García-Bellido en el recorrido por plazas, naves, pasajes y calles del recinto de Can Ricart, al hallarse inesperadamente ante un conjunto fabril de dimensiones y rasgos singulares, fue grande. Javier analizó sus características y valoró e interpretó su significado como pieza arquitectónica representativa de un momento histórico (1853) en que un empresario del sector textil (Jaume Ricart) invirtió cuantiosos recursos económicos en un conjunto encargado al arquitecto y académico Josep Oriol Bernadet, continuado después por el conocido maestro de obras Josep Fontseré Mestre. Javier destacó su valor representativo y simbólico, ya que, a pesar de estar dedicado a una nueva e innovadora función industrial, como era la producción de tejidos estampados a gran escala y con máquinas de vapor, constituía una pieza de gran valor arquitectónico-artístico por sus caracteres estilísticos propios del neoclasicismo romántico.

De sus palabras recuerdo, ahora, que manifestó su admiración ante el potente conjunto fabril que 150 años después se mantenía en pie, sin apenas modificación en su estructura y trazas originales, y que emergía con su bella secuencia de naves presididas por la torre y la chimenea en medio del paisaje industrial de un Poblenou en profunda transformación. Tal como observó, por primera vez en España un recinto fabril de iniciativa privada aunaba en un solo espacio función productiva y belleza arquitectónica, destacando por el afán de notoriedad y representatividad del poder técnico, económico y social de su propietario.

Su admiración por el recinto y su apoyo incondicional a nuestra lucha por la conservación íntegra de Can Ricart, iniciada el año 2003, creo que se debía a una razón esencial. Nuestra reivindicación reúne buena parte de los elementos sobre los que el pretendía trabajar en el estudio del proceso de derribo de las murallas de Barcelona, y que están presente en el debate por la conservación del recinto de Can Ricart: modernización arquitectónica, debate sobre las murallas como espacio de frontera entre el densificado interior de la ciudad y los amplios y vacíos espacios exteriores, grandes recintos fabriles privados frente a las manufacturas de iniciativa real, y papel de las figuras y personajes de la política, la técnica y la cultura de mediados siglo XIX en las transformaciones urbanísticas.

Sin olvidar que Can Ricart había sido una de las primeras fabricas que con su implantación en Sant Martí en cierta manera inició el fenómeno que hoy conocemos como ciudad difusa, al llevar la expansión urbana a terrenos fuera murallas, en pleno debate sobre la ubicación de los barrios industriales y obreros; dichas temáticas también fueron muy próximas al quehacer profesional e intelectual de García-Bellido 
En este marco, la figura de Josep Oriol Bernadet emergía como uno de los grandes desconocidos de este periodo, al que no se había de dedicado hasta nuestro trabajo ninguna biografía, y en el que, por diversas razones, otros arquitectos han merecido una mayor valoración posterior.

La trayectoria profesional, técnica y científica de Josep Oriol presenta muchos aspectos de coincidencia con los puntos de interés de García- Bellido por la gestión del derribo de las murallas y sus protagonistas.

Josep Oriol Bernadet nació en 1811 en la población gerundense del Far de l'Ampurdá cercana a Figueres (Girona) y, tras sus estudios en la Junta de Comercio de Barcelona, obtuvo el título de arquitecto por la Real Academia de San Fernando de Madrid en 1833. En su trayectoria profesional como arquitecto destacan, además del recinto fabril de Can Ricart y de otros trabajos de carácter arquitectónico y urbanístico, dos de las grandes obras españolas de mediados del siglo XIX vinculadas a los nuevos espacios dedicados a la salud como fueron el balneario de la Puda de Montserrat (1846), en la población catalana de Olesa de Montserrat, y el proyecto del Hospital Mental de la Santa Cruz (1858) en Barcelona; ambos conjuntos han sido ampliamente valorados por especialistas de la historia de la medicina y de la historia termal como los primeros de su género con características innovadoras levantados en España, y habrían de servir de ejemplo para otros similares construidos en diversas ciudades.

En la figura de Josep Oriol Bernadet destaca otro aspecto profesional que también interesó a Javier García-Bellido después de conocer el recinto fabril de Can Ricart. Se trata de su actuación como arquitecto municipal de Sabadell entre 1842 i 1856, periodo en el que proyectó un plan de Ensanche y en que fue autor del Hospital-Casa de Beneficencia y de la Pescadería.

La trayectoria de este arquitecto catalán como científico y profesor de centros educativos de rango superior (Escuela Industrial Barcelonesa, Instituto de Segunda Enseñanza vinculado entonces a la Universidad, Junta de Comercio, Sociedad Económica de Amigos del País) también ha sido glosada por algunos especialistas e historiadores de la ciencia y de la economía, que reseñamos con detalle en la nota biográfica que publicamos en el año 2005 y que actualmente continuamos ampliando.

Josep Oriol Bernadet forma parte de la misma generación que Madoz y que Cerdà, nacidos en 1805 y en 1815, respectivamente. Respecto al último ya destacamos en otro trabajo su vinculación con Oriol, primero en la Escuela de la Junta de Comercio de Barcelona, en la que Cerdá realizó una breve estancia de estudios antes de su marcha a Madrid para estudiar en la Escuela de Ingenieros de Caminos; después, la coincidencia de ambos en las obras del ferrocarril de Barcelona a Granollers cuando, en 1851, la dirección facultativa de dichas obras corrió a cargo de Josep Oriol Bernadet mientras que Ildefonso Cerdà dirigía los trabajos de explanación.

Precisamente, el trazado de este ferrocarril puso en cuestión las murallas barcelonesas como elemento limitador a la expansión urbana y al desarrollo de las nuevas infraestructuras de transporte. El tema solo ha sido parcialmente tratado en los estudios sobre esta línea de ferrocarril, que tenía gran importancia para las comunicaciones de Barcelona con las minas de carbón de Ogassa que tantas expectativas despertaba. 
La historia de esta línea inaugurada en 1854 -el segundo trazado ferroviario catalán después del de Mataró- muestra como, después de diversas gestiones, sus promotores, con el financiero e industrial Manuel Girona al frente, consiguieron ubicar la estación dentro del perímetro defensivo de la ciudad, atravesando la muralla por dos túneles a los que sobrepusieron una pequeña estructura defensiva. Para llegar a dicha estación, localizada en el punto neurálgico de la ciudad que era entonces el Pla de Palau, se vieron obligados a realizar una gran curva bordeando la Ciudadela.

No conocemos con detalle los pormenores de las negociaciones llevadas a cabo entre el Ramo de Guerra, el Ministerio de Fomento y el propio Ayuntamiento, las cuales, sin duda, habrían interesado en sobremanera a Javier García-Bellido, puesto que significaron un primer paso en el camino hacia la desmilitarización de la ciudad y contribuyeron al debate sobre el papel defensivo de las murallas y la necesidad de su desaparición.

Javier García-Bellido nos devolvió con sus estudios sobre Pascual Madoz e Ildefonso Cerdá y con su proyecto de investigación sobre el derribo de las murallas el interés por el estudio de estas décadas centrales del ochocientos, que fueron para Barcelona cruciales en muchos sentidos. Desafortunadamente él no está aquí para seguirlos, pero esperamos que la investigación que inició pueda ser continuada y que contemos pronto con un material documental de primera mano que nos proporcione un mejor conocimiento de este apasionante periodo de la historia de la ciudad; durante el mismo se decretó el derribo de las murallas y se inició en Ensanche, se impulsó la industrialización y se pusieron de manifiesto una buena parte de los temas y conflictos urbanísticos (reparcelación, liberalización de suelo, plusvalías, gestión publica del suelo urbano y propiedad inmobiliaria..) que han acompañado hasta hoy el desarrollo de nuestras ciudades, y que fueron objeto de las preocupaciones y de los estudios de Javier García-Bellido a lo largo de su vida profesional y académica.

Por otra parte, su trabajo sobre Pascual Madoz nos aproxima de una forma muy precisa a las relaciones difíciles, pero no por ello menos fructíferas, entre las dos grandes ciudades españolas de entonces y de hoy que son Madrid y Barcelona. La figura de los técnicos, científicos, políticos y empresarios, y las relaciones entre unos y otros en este momento de la historia de España, no pueden entenderse sin conocer con detalle las profundas interacciones entre las dos ciudades desde las cuales se dirimían conflictos, se desarrollaban iniciativas y se establecían redes personales y económicas, e incluso vínculos personales, mas allá del mundo de los negocios y de la política. Formas de interacción que interesaron a Javier GarcíaBellido en su afán por comprender y explicar procesos urbanísticos, y que nos obligaban a los investigadores catalanes a pensar en ellas, incluso cuando se tratada de analizar un elemento concreto como eran las murallas de Barcelona y la venta y urbanización de sus terrenos. De este modo Javier estableció puentes y diálogos entre dos ciudades, tal como quedó muy claro con su importante participación en el IX Congreso de Historia de Barcelona celebrado en noviembre de 2005, en el que presentó una excelente comunicación sobre Pascual Madoz y el derribo de las murallas, realizada conjuntamente con Sara Anna Mangiagalli.

Esperamos que el recuerdo de su trayectoria profesional y del entusiasmo vital que le caracterizó nos sirva para poder mantener vivos estos puentes y estos diálogos a pesar de que él no siga aquí con nosotros. 


\section{BIBLIOGRAFÍA}

Alcalde, Gonzalez R., El ferrocarril como elemento estructurador de la morfología urbana. El caso de Barcelona 1848-1900. Scripta Nova. Revista Electrónica de Geografía y Ciencias Sociales, Universidad de Barcelona, vol IX, núm. 194(65), agosto 2005. Universidad de Barcelona. <http://www.ub.es/geocrit/sn-194-65.htm>.

Benet, J. Marti, C., Barcelona a mitjan segle XIX, Barcelona Curial, 19762 vols.

García-Bellido, J, Ildefonso Cerdá y su poderoso influjo en el urbanismo español del último siglo y medio, Ciudad y Territorio. Serie Monografías, Madrid Ministerio de Fomento, 2004.

García-Bellido, J., Mangiagali, S. A, Pascual Madoz y el derribo de las murallas en el inicio del Eixample de Barcelona, Comunicación presentada al IX Congreso de Historia de Barcelona, Barcelona, Ayuntamiento de Barcelona-Instituto Municipal de historia, 2005, (edición electrónica en publicación).

Larrosa M., La urbanización de la ciudad industrial, Sabadell 1845-1980, Sabadell, Delegación del Colegio de Doctores y Licenciados del Colegio de Arquitectos de Cataluña, 1986.

Lusa, G.; Roca, A., Historia de la ingeniería industrial en Barcelona. Documentos de la Escuela de Ingenieros Industriales, Barcelona, núm. 15,2005.

Mangiagali, S. A., Barcelona 1854-1856: Crónicas del Ensanche de Antonio Brusi, Revista ACE vol 1, núm 1 págs.29-45. 2006.

Morales, G.; García-Bellido, J.; Asis, A., Pascual Madoz (1805-1870. Un político transformador del territorio, Madrid, Universidad Carlos III de Madrid, 2005.

Montaner, J.Ma . La modernización de la arquitectura a Catalunya 1714-1859, Barcelona, Institut d'Estudis Catalans, 1990.

Segarra, F.: Barcelona ciutat de transició (1848-1868. El projecte urbà a traves dels treballs de l'arquitecte Miquel Garriga y Roca, Barcelona, Institut d'Estudis Catalans, 1996.

Sola, A.: L'elit barcelonina de mitjan segle XIX. Tesis Doctoral, Universidad de Barcelona, 1977. 3 vols.

Tatjer, M.; Urbiola, M. i Grup de Patrimoni Industrial del Forum, ribera del besos: Estudi patrimonial de Can Ricart (Sintesi), Biblio3 W, Revista bibliográfica de Geografia y Ciencias Sociales, Universidad de Barcelona, Vol, X, núm. 598.<http://www.ub.es/geocrit/b3w 598.htm>.

Tatjer, M.; Urbiola, M.: Can Ricart (1853). Entre la tradició i la modernitat en l'arquitectura industriual catalana de mitjans segle XIX, IX Congreso de Historia de Barcelona, Barcelona, Ayuntamiento de Barcelona, Instituto Municipal de Historia de Barcelona, 2005 (edición electrónica en publicación). 
Tatjer M. Josep Oriol Bernadet i la seva aportació a la història de la ciencia, de la tècnica i de l'arquitectura catalana del segle XIX. Apunts per una biografia, Biblio3W Revista bibliográfica de Geografia y Ciencias Sociales, Universidad de Barcelona, Vol, X, núm 582, 10 de mayo 2005. <http://www.ub.es/geocri t/b3w 582.htm>.

Tatjer, M. Fontseré a Can Ricart. La construcción de la fabrica de Can Ricart i l'actuació de Josep Fontseré i Mestre, Biblio3W Revista Bibliográfica de Geografia y Ciencias Sociales, Universidad de Barcelona, Vol, X, núm 607, 10 de octubre 2005.

<http://www.ub.es/geocrit/b3w 607.htm>.

Tatjer, M.: La indústria a l'Eixample de Barcelona: el sector de Sant Antoni, 1860-1874, IX Congreso de Historia de Barcelona, Barcelona, Ayuntamiento de Barcelona- Instituto Municipal de Historia de Barcelona, 2005. (Edición electrónica en publicación). 